\title{
Implementation of a Compressor Face Boundary Condition Based on Small Disturbances
}

John W. Slater

Glenn Research Center, Cleveland, Ohio

Gerald C. Paynter

The Boeing Company, Seattle, Washington 
Since its founding, NASA has been dedicated to the advancement of aeronautics and space science. The NASA Scientific and Technical Information (STI) Program Office plays a key part in helping NASA maintain this important role.

The NASA STI Program Office is operated by Langley Research Center, the Lead Center for NASA's scientific and technical information. The NASA STI Program Office provides access to the NASA STI Database, the largest collection of aeronautical and space science STT in the world. The Program Office is also NASA's institutional mechanism for disseminating the results of its research and development activities. These results are published by NASA in the NASA STI Report Series, which includes the following report types:

- TECHNICAL PUBLICATION. Reports of completed research or a major significant phase of research that present the results of NASA programs and include extensive data or theoretical analysis. Includes compilations of significant scientific and technical data and information deemed to be of continuing reference value. NASA's counterpart of peerreviewed formal professional papers but has less stringent limitations on manuscript length and extent of graphic presentations.

- TECHNICAL MEMORANDUM. Scientific and technical findings that are preliminary or of specialized interest, e.g., quick release reports, working papers, and bibliographies that contain minimal annotation. Does not contain extensive analysis.

- CONTRACTOR REPORT. Scientific and technical findings by NASA-sponsored contractors and grantees.
- CONFERENCE PUBLICATION. Collected papers from scientific and technical conferences, symposia, seminars, or other meetings sponsored or cosponsored by NASA.

- SPECIAL PUBLICATION. Scientific, technical, or historical information from NASA programs, projects, and missions, often concerned with subjects having substantial public interest.

- TECHNICAL TRANSLATION. Englishlanguage translations of foreign scientific and technical material pertinent to NASA's mission.

Specialized services that complement the STI Program Office's diverse offerings include creating custom thesauri, building customized data bases, organizing and publishing research results ... even providing videos.

For more information about the NASA STI Program Office, see the following:

- Access the NASA STI Program Home Page at http://www.sti.nasa.gov

- E-mail your question via the Internet to help@sti.nasa.gov

- Fax your question to the NASA Access Help Desk at (301) 621-0134

- Telephone the NASA Access Help Desk at (301) 621-0390

- Write to: NASA Access Help Desk NASA Center for AeroSpace Information 7121 Standard Drive Hanover, MD 21076 
NASA/TM-2000-209945

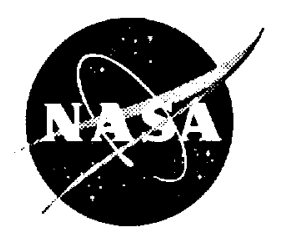

\section{Implementation of a Compressor Face Boundary Condition Based on Small Disturbances}

John W. Slater

Glenn Research Center, Cleveland, Ohio

Gerald C. Paynter

The Boeing Company, Seattle, Washington

Prepared for the 45th International Gas Turbine and Aeroengine Technical Congress sponsored by the American Society of Mechanical Engineers Munich, Germany, May 8-11, 2000

National Aeronautics and Space Administration

Glenn Research Center 


\section{Acknowledgments}

The authors would like to thank Mr. Gary L. Cole of the NASA Glenn Research Center and Professor Miklos Sajben of the University of Cincinnati for important insights and corrections to this work. Mr. Cole also provided the LAPIN results.

This report contains preliminary findings, subject to revision as analysis proceeds.

This report is a preprint of a paper intended for presentation at a conference. Because of changes that may be made before formal publication, this preprint is made available with the understanding that it will not be cited or reproduced without the permission of the author.

Available from

NASA Center for Aerospace Information 7121 Standard Drive

Hanover, MD 21076

Price Code: $\mathrm{A} 03$
National Technical Information Service 5285 Port Royal Road Springfield, VA 22100

Price Code: A03 


\section{IMPLEMENTATION OF A COMPRESSOR FACE BOUNDARY CONDITION BASED ON SMALL DISTURBANCES}

\author{
John W. Slater \\ John H. Glenn Research Center at Lewis Field, MS 86-7 \\ 21000 Brookpark Road, Cleveland, Ohio 44135, USA \\ Phone: (216) 433-8513, Fax: (216) 433-7500 \\ Email: john.w.slater@grc.nasa.gov
}

\author{
Gerald C. Paynter \\ The Boeing Company, MS 67-LF \\ P.O. Box 3707, Seattle, Washington 98124, USA \\ Phone: (425) 234-9160, Fax: (425) 237-8281 \\ Email: gerald.c.paynter@boeing.com
}

\begin{abstract}
A compressor-face boundary condition that models the unsteady interactions of acoustic and convective velocity disturbances with a compressor has been implemented into a three-dimensional computational fluid dynamics code. Locally one-dimensional characteristics along with a small-disturbance model are used to compute the acoustic response as a function of the local stagger angle and the strength and direction of the disturbance. Simulations of the inviscid flow in a straight duct, a duct coupled to a compressor, and a supersonic inlet demonstrate the behavior of the boundary condition in relation to existing boundary conditions. Comparisons with experimental data show a large improvement in accuracy over existing boundary conditions in the ability to predict the reflected disturbance from the interaction of an acoustic disturbance with a compressor.
\end{abstract}

\section{NOMENCLATURE}

\section{Roman Letters}

\section{C}

$M$

$S \quad$ Circumferential spacing of compressor blades

$U \quad$ Desired axial velocity at compressor face

a Acoustic speed

$e \quad$ Specific internal energy

$p \quad$ Static pressure

$r \quad$ Radial coordinate

$t \quad$ Time

$u, v, w \quad$ Cartesian velocity components
$u, w_{r}, v_{\theta}$
Velocity components in fixed frame
$u, \tilde{w}_{r}, \tilde{v}_{\theta}$
Velocity components in blade frame
$x, y, z$
Cartesian coordinates

\section{Greek Letters}

$\alpha \quad$ Convective velocity response coefficient

$\beta \quad$ Acoustic response coefficient

$\delta \quad$ Small discrete difference

$\gamma \quad$ Ratio of specific heats $(\gamma=1.4$ for air)

$\Gamma \quad$ Stagger angle

$\rho \quad$ Density

$\sigma \quad$ Local Courant number

$\theta \quad$ Circumferential cylindrical coordinate

$\begin{array}{ll}\text { Subscripts } & \text { Superscripts } \\ a & \text { Solution point adjacent to boundary } \\ \text { acoustic } & \text { Component due to acoustic disturbance } \\ b & \text { Solution point at boundary } \\ \text { case } & \text { Location on case } \\ \text { convective } & \text { Component due to convective disturbance } \\ c f & \text { Compressor face } \\ h u b & \text { Location on hub } \\ n & \text { Time level for known state } \\ n+1 & \text { Time level for new state } \\ \text { passage } & \text { Conditions within the blade passage } \\ r & \text { Radial } \\ x & \text { Axial } \\ \theta & \text { Circumferential }\end{array}$




\section{INTRODUCTION}

The aerodynamic analysis of the flow in an aircraft inlet for a turbine engine system may involve the analysis of unsteady flow. For example, atmospheric disturbances in pressure or flow angle ingested into a supersonic inlet may interact with the compressor and reflect acoustic waves which may cause instabilities in the shock system and cause unstart (Mayer and Paynter, 1994).

Acoustic disturbances are changes in pressure which travel at the speed of sound relative to the local fluid velocity. They can travel upstream, as well as, downstream. Velocity disturbances are convected at the local fluid velocity, and so, can only travel downstream. Here we are interested in disturbances that travel downstream through the duct, interact with the compressor, and generate an upstream-travelling acoustic disturbance.

The analysis of flows in inlets using computational fluid dynamics generally use flow domains in which the compressor face is a boundary and some appropriate outflow boundary condition is applied. The alternative is to include the compressor or the entire engine into the flow domain (Suresh et al., 1999). The latter approach involves considerably more computational resources and is not currently considered practical for design studies.

Several outflow boundary conditions have been used. Since the outflow is subsonic, only one physical quantity needs to be imposed. Most boundary conditions have held a quantity fixed, such as pressure, corrected mass flow (Mayer and Paynter, 1994), Mach number (Mayer and Paynter, 1994) (Chung and Cole, 1995), or velocity (Mayer and Paynter, 1994)(Paynter, 1998). However, for unsteady flows, such quantities may not be fixed. Experiments have been performed to investigate the unsteady nature of disturbances interacting with compressors (Freund and Sajben, 1997). This has led to an analytic study (Sajben, 1999). Paynter has investigated a compressor-face boundary condition that models the unsteady interactions of acoustic (Paynter, 1997) (Paynter, Clark and Cole, 1998) and convective velocity (Paynter, 1998) disturbances with a compressor using locally one-dimensional characteristics along with a small-disturbance model. The reflected acoustic response is computed as a function of the local stagger angle and the strength and direction of the disturbance. Paynter et al. (1998) implemented this boundary condition into two one-dimensional codes and demonstrated that it improved the simulation of the response to acoustic disturbances. The current paper addresses the implementation of the Paynter small-disturbance compressor-face boundary condition into the three-dimensional NPARC code (Chung et al., 1999).

The Paynter small-disturbance compressor-face boundary condition is summarized and an outline is presented of how the boundary condition was implemented. The behavior of the boundary condition is examined in comparison with existing outflow boundary conditions and limited experimental data.

\section{FRAMES OF REFERENCE}

The computational fluid dynamic methods operate in a Cartesian $(x, y, z)$ frame-of-reference. For axial flow compressors, a cylindrical $(x, \theta, r)$ frame is useful. At the compressor face, the inlet is assumed to be a constant-area annulus with the axial coordinate denoted as $x$. The circumferential coordinate $\theta$ is coincident with the direction of compressor rotation. The radial coordinate $r$ is perpendicular to the $x-\theta$ surface. A blade-fixed frame has the cylindrical frame rotating with the fan blade.

\section{SUMMARY OF THE CASCADE COMPUTATIONS AND THE FORMULATION OF A COMPRESSOR MODEL}

Paynter (Paynter, 1997) (Paynter, Clark and Cole, 1998) performed two-dimensional, time-accurate Euler flow simulations with step acoustic and convective velocity disturbances interacting with a two-dimensional cascade. The responses were examined with respect to the stagger angle, solidity, axial Mach number, blade loading, blade shape, and disturbance strength. Some of the assumptions and major results are summarized here with respect to the formulation of a model for the compressor face.

1. The compressor face consists of a single row of blades. This is equivalent to saying that all reflected waves are due to interactions with the first stage. Actually, compressors may consists of several stages and waves transmitted through the first stage may reflect from later stages and propagate upstream through the initial stages.

2. The volume of the blade passage is negligible relative to the volume of the annular section of the inlet.

3. The rotational speed of the compressor is constant.

4. The stagger angle $\Gamma$ of the compressor blade varies linearly in the radial direction,

$$
\Gamma(r)=\Gamma_{h u b}+\frac{r-r_{h u b}}{r_{c a s e}-r_{h u b}}\left(\Gamma_{c a s e}-\Gamma_{h u b}\right) .
$$

5. $u>>\left(v, v_{\theta}, \tilde{v}_{\theta}, w, w_{r}, \tilde{w}_{r}\right)$.

6. The flow properties prior to the disturbance are known.

7. Acoustic disturbances propagate axially.

8. Acoustic disturbances yield an acoustic response.

9. Convective axial velocity disturbances are not possible.

10. Convective tangential velocity disturbances are possible and yield an acoustic response. The effect is a local change in the flow angle-of-attack with respect to the compressor blade. The response pressure decreases or increases depending on whether the velocity relative to the blade is increased or decreased, respectively.

11. Convected disturbances are convected axially from the "adjacent" to the "boundary" grid planes without change.

12. Radial variations in the velocity do not significantly influence the production of the reflected acoustic responses. 
13. The response is not a strong function of blade loading, therefore, the compressor blades are assumed to be unloaded. This implies that the flow is attached (unstalled). Further, the compressor blades are assumed to be flat and of zero thickness. Thus, the flow angle is initially aligned with the blades and is equal to the stagger angle. In the blade-fixed frame, the tangential velocity component is then given by

$$
\tilde{v}_{\theta c f}=u_{c f} \tan \Gamma
$$

This allows the passage Mach number to be determined as

$$
M_{\text {passage }}=M_{c f} / \cos \Gamma
$$

14. The response becomes insensitive to solidity for solidities greater than one. Therefore, the compressor blades are assumed to have a solidity greater than 1.0 .

15. If the passage flow is subsonic, the turning of the flow starts at the reflected disturbance and ends well into the blade passage. If the flow is supersonic all of the turning occurs at the reflected disturbance upstream of the blade passage.

16. Four distinct flow regions can be identified and are shown in Figs. 1 and 2. Region 1 is prior to any disturbance. Region 2 is just after the disturbance has passed. Region 3 is between the cascade leading edge and the response. Region 4 is in the blade passage and downstream of the blade passage that is upstream of the transmitted disturbance.

17. A step increase pressure disturbance causes an increase in the axial velocity between regions 1 and 2 . The tangential component of velocity is unchanged between regions $I$ and 2. For an initially unloaded cascade, this means that the flow in region 2 is no longer aligned with the blade passage. For weak disturbances, the changes in static flow properties between regions $I$ and 2 are isentropic. The total properties in a blade frame of reference are different in regions 1 and 2 because the disturbance separates these regions.

18. For a step change in the tangential velocity being convected by the initial axial velocity the axial velocity and static pressure are unchanged between regions $I$ and 2 . For an initially unloaded cascade, this means that the flow in region 2 is no longer aligned with the blade passage. Although the static properties are the same in regions $I$ and 2 , the total properties are different because of the change in velocity.

19. The tangential component of velocity is unchanged across the left running acoustic disturbance. Since only the axial component of velocity is changed, the reflected disturbance is a plane wave. The changes in static properties across the reflected disturbance are isentropic.

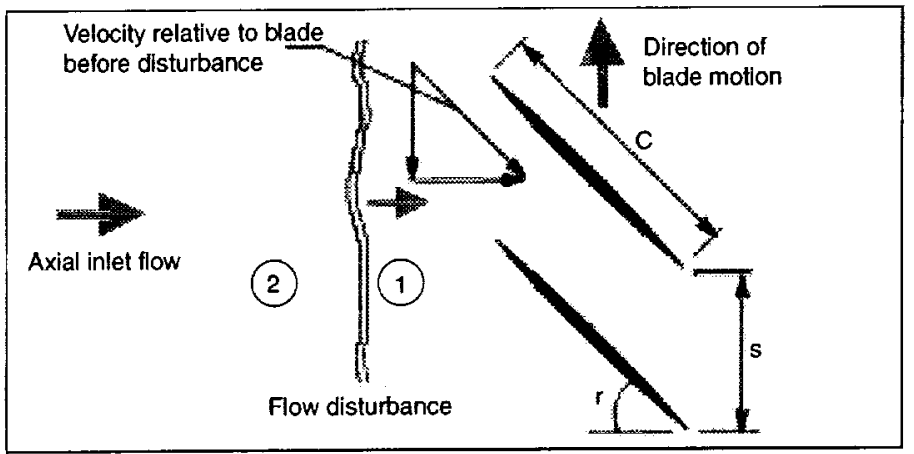

Figure 1. FLOW SCHEMATIC PRIOR TO THE DISTURBANCE / BLADE PASSAGE INTERACTION. THE DISTURBANCE APPROACHES THE BLADE PAIR FROM THE LEFT.

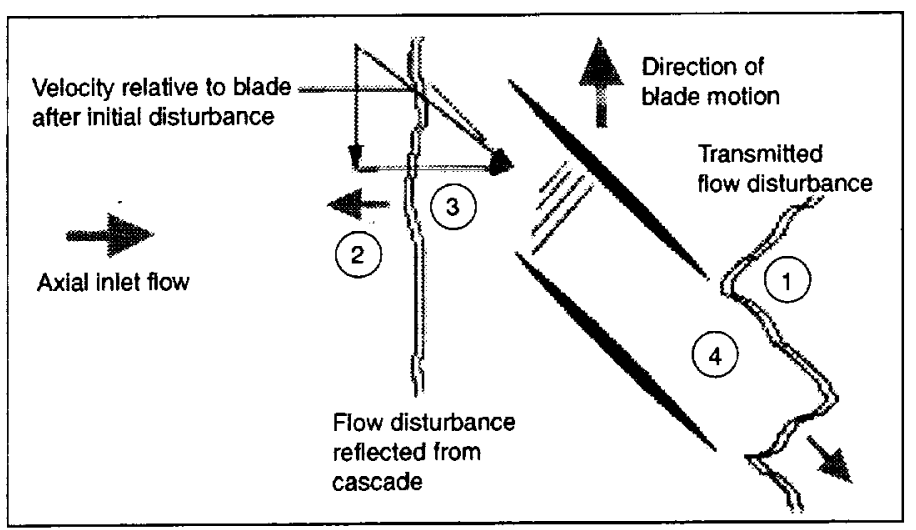

Figure 2. FLOW SCHEMATIC AFTER THE DISTURBANCE / BLADE PASSAGE INTERACTION. AN ACOUSTIC DISTURBANCE TRAVELS UPSTREAM TO THE LEFT.

\section{ACOUSTIC RESPONSE COEFFICIENT}

The acoustic response coefficient is defined as

$$
\beta \equiv\left(p_{3}-p_{2}\right) /\left(p_{2}-p_{1}\right)
$$

Paynter (Paynter, 1998) and Sajben (Sajben, 1999) have each developed an expression for the acoustic response coefficient for the response from a compressor face for a small step acoustic disturbance. Both approaches derive the response coefficient by forming a system of linear equations based on the continuity, momentum, and energy equations and using the smalldisturbance and isentropic assumptions along with the characteristic relations of the one-dimensional flow.

Paynter's acoustic response coefficient depends on whether the Mach number in the blade passage is subsonic or supersonic. 
For subsonic passage flow $\left(M_{\text {passage }}<1\right)$,

$$
\beta\left(M_{c f}, \Gamma\right)=\tan ^{2}\left(\frac{\Gamma}{2}\right)\left(\frac{1+M_{c f}}{1-M_{c f}}\right)
$$

For supersonic passage flow $\left(M_{\text {passage }}>1\right)$,

$$
\beta\left(M_{c f}, \Gamma\right)=1.0
$$

Sajben's acoustic response coefficient is

$$
\beta\left(M_{c f}, \Gamma\right)=\left(\frac{1+M_{c f}}{1-M_{c f}}\right)\left(\frac{M_{c f} \tan ^{2} \Gamma}{2\left(1+M_{c f}\right)+M_{c f} \tan ^{2} \Gamma}\right)
$$

One can obtain a non-reflective condition by imposing $\beta=$ 0.0 . When $\beta=-1.0$, one recovers the constant-pressure boundary condition. When $\beta=1.0$, one recovers a constant-velocity boundary condition.

\section{CONVECTIVE VELOCITY RESPONSE COEFFICIENT}

The convective velocity response coefficient is defined as

$$
\alpha \equiv \frac{\left(p_{3}-p_{2}\right) / p_{1}}{\left(v_{\theta 2}-v_{\theta 1}\right) / v_{\theta 1}}
$$

Paynter (1998) has developed a velocity response coefficient using similar methods as for the acoustic response coefficient. Since axial velocity disturbances result in axial acoustic disturbance, we consider here only step circumferential velocity disturbances, $\delta v_{\theta}$. Thus the static pressure, static temperature, and axial velocities all remain unchanged.

The expression for the velocity response coefficient $\alpha\left(M_{c f}, \Gamma\right)$ is dependent on whether the Mach number of the flow into the blade passage is subsonic or supersonic. For subsonic passage flow $\left(M_{\text {passage }}<1\right)$,

$$
\alpha\left(M_{c f}, \Gamma\right)=\frac{\gamma M_{c f}^{2}}{1-M_{c f}} \tan \left(\frac{\Gamma}{2}\right) \tan \Gamma
$$

For supersonic passage flow $\left(M_{\text {passage }}>1\right)$,

$$
\alpha\left(M_{c f}, \Gamma\right)=\gamma M_{c f}
$$

\section{SMALL DISTURBANCE BOUNDARY CONDITION}

The two central ideas of the Paynter small-disturbance boundary condition are that both acoustic and convective velocity disturbances result in upstream-propagating acoustic respōnses, and that the acoustic responses are a simple linear combination of the individual responses due to acoustic and convective disturbances. Thus, a simple time difference can be applied to the static pressure at the boundary with respect to the linear combination of responses,

$$
p_{b}^{n+1}=p_{b}^{n}+\delta p_{\text {acoustic }}+\delta p_{\text {convective }}
$$

The response due to an acoustic disturbance is

$$
\delta p_{\text {acoustic }}=\sigma\left[1+\beta\left(M_{c f}, \Gamma\right)\right]\left(p_{a}^{n}-p_{b}^{n}\right)
$$

The subscript $a$ denotes the solution point adjacent to the boundary in the direction normal to the boundary. The $\sigma$ is the local Courant number,

$$
\sigma=(u+a)_{b} \frac{t^{n+1}-t^{n}}{x_{b}-x_{a}}
$$

The time step is chosen such that $\sigma<1.0$ at the boundary.

The response due to a convective velocity disturbance is

$$
\delta p_{\text {convective }}=-\alpha\left(M_{c f}, \Gamma\right) \sigma\left(\frac{M_{x b}^{n}}{M_{x b}^{n}+1}\right) \frac{p_{b}^{n}\left(v_{\theta a}^{n}-v_{\theta b}^{n}\right)}{U_{c f} \tan \Gamma+v_{\theta b}^{n}}(14)
$$

The $M_{x b}$ is the local axial Mach number at the boundary,

$$
M_{x b}=u_{b} / a_{b}
$$

Analogous to Eq. 11, the axial velocity can be expressed as,

$$
u_{b}^{n+1}=u_{b}^{n}+\delta u_{\text {acoustic }}+\delta u_{\text {convective }}
$$

where,

$$
\delta u_{a c o u s t i c}=\frac{a_{b}^{n}\left[1-\beta\left(M_{c f}, \Gamma\right)\right]}{\gamma p_{b}^{n}\left[1+\beta\left(M_{c f}, \Gamma\right)\right]} \delta p_{a c o u s t i c}
$$

and

$$
\delta u_{\text {convective }}=-\frac{a_{b}^{n}}{\gamma p_{b}^{n}} \delta p_{\text {convective }}
$$




\section{IMPLEMENTATION OF THE BOUNDARY CONDITION}

The implementation of the boundary condition into the NPARC code required that the conservative variables $(\rho, \rho u, \rho v, \rho w, \rho e)$ be computed at each grid point on the boundary at each time step. The computational requirements were no greater than required for other outflow boundary conditions in NPARC. The steps of the implementation include:

1. Properties $(p, \rho, u, v, w, a, M)$ are computed at the "boundary" and "adjacent" grid points for the $n$-th time level.

2. The stagger angle is computed using Eq. 1 .

3. The local Courant number is computed using Eq. 13.

4. The passage Mach number is computed using Eq. 3.

5. The convective velocity response coefficient $\alpha\left(M_{c f}, \Gamma\right)$ is computed using either Eq. 9 or 10.

6. The Cartesian velocity components are transformed to the fixed cylindrical frame of reference.

7. The $\delta p_{\text {convective }}$ is computed using Eq. 14.

8. The acoustic response coefficient $\beta$ is computed using Eq. 5 or 6 .

9. The $\delta p_{\text {acoustic }}$ is computed using Eq. 12 .

10. The pressure at the new time level is computed using Eq. 11.

11. The density at the new time level is computed as

$$
\begin{aligned}
\rho_{b}^{n+1} & =\rho_{b}^{n}+\frac{1}{\left(a_{b}^{n}\right)^{2}}\left(p_{b}^{n+1}-p_{b}^{n}\right) \\
+ & \left(\frac{\sigma M_{x b}^{n}}{M_{x b}^{n}+1}\right)\left[\frac{\rho_{b}^{n}}{\gamma p_{b}^{n}}\left(p_{b}^{n}-p_{a}^{n}\right)-\left(\rho_{b}^{n}-\rho_{a}^{n}\right)\right]
\end{aligned}
$$

12. The axial velocity component at the new time level is computed using Eq. 16.

13. The cylindrical velocity components in the fixed frame for the new time level are computed as

$$
v_{\theta b}^{n+1}=v_{\theta b}^{n}+\sigma\left(\frac{M_{x b}^{n}}{M_{x b}^{n}+1}\right)\left(v_{\theta a}^{n}-v_{\theta b}^{n}\right) .
$$

and

$$
w_{r b}^{n+1}=w_{r b}^{n}+\sigma\left(\frac{M_{x b}^{n}}{M_{x b}^{n}+1}\right)\left(w_{r a}^{n}-w_{r b}^{n}\right) .
$$

14. The velocity components in the fixed cylindrical frame are transformed back into the fixed Cartesian frame.

15. The total energy for the new time level is computed as

$$
\begin{aligned}
(\rho e)_{b}^{n+1} & =(\rho e)_{b}^{n}+\frac{\left(p_{b}^{n+1}-p_{b}^{n}\right)}{\gamma-1}+\frac{\left(u_{b}^{n}\right)^{2}}{2}\left(\rho_{b}^{n+1}-\rho_{b}^{n}\right) \\
& +(\rho u)_{b}^{n}\left(u_{b}^{n+1}-u_{b}^{n}\right)
\end{aligned}
$$

16. The procedure is repeated for each boundary grid point.

\section{RESULTS}

The following results demonstrate the behavior of the Paynter small-disturbance compressor-face boundary condition in relation to other boundary conditions with comparisons to the limited experimental data for interactions with compressors.

\section{STEP DISTURBANCES IN A STRAIGHT DUCT}

This case examined the unsteady, inviscid flow in a straight, annular duct created when downstream-travelling step disturbances interact with the outflow boundary modelled with various outfiow boundary conditions. The compressor was assumed to have fan blades with stagger angles varying from 45 degrees at the hub to 60 degrees at the case. The steady-state compressorface Mach number was 0.2 .

The acoustic disturbance was imposed by initializing the flow field in the first quarter of the duct with a $+10 \%$ step pressure perturbation. The step propagated downstream as a pure acoustic wave. Figure 3 shows the response at a sensor located at the three-quarters axial location for the various boundary condjtions. At approximately $t=0.62 \mathrm{msec}$, the incident wave reached the sensor and the static pressure steped up $10 \%$. Some "ringing" or "oscillation" was noticed, which is due to numerical dispersion. The wave passed by, interacted with the compressor face and the reflected, upstream-travelling wave reached the sensor at approximately $t=1.43 \mathrm{msec}$. The different behavior of the various boundary conditions became apparent at that time and agreed quite well with the expected behavior. The constant-pressure boundary condition resulted in an expansion wave that canceled out the incident wave. The non-reflective boundary condition $(\beta=0)$ show that the incident wave exited the outflow boundary. The time histories for the Chung-Cole and Mayer-Paynter constant-Mach number boundary conditions show the correct sign for the reflected response with a magnitude approximately equal to that of the disturbance. Similar results were obtained with the constant-velocity boundary condition $(\beta=1)$. The plot shows the Paynter small-disturbance boundary condition predicting a response of about $4 \%$ of the steady-state pressure. The plot labeled "Sajben" is Paynter's small-disturbance boundary condition using Sajben's acoustic response coefficient (Eq. 7).

The radial variation of the acoustic response coefficient $\beta$ for a given compressor-face Mach number can be calculated using Eqs. 5 or 7 along with Eq. 1. If one evaluates the response coefficient for the minimum, area-weighted average, and maximum stagger angles, one obtains the vertical lines presented at the right in Fig. 3. The Paynter expression (Eq. 5) predicts a stronger response than the Sajben expression (Eq. 7) and its overall response is dominated by the higher stagger angles.

The responses of the boundary conditions to circumferential velocity perturbations of $+10 \%$ and $-10 \%$ of the axial velocity are presented in Fig. 4. The disturbance reached the sensor at a time of $t=3.7 \mathrm{msec}$; however, nothing was observed since no 


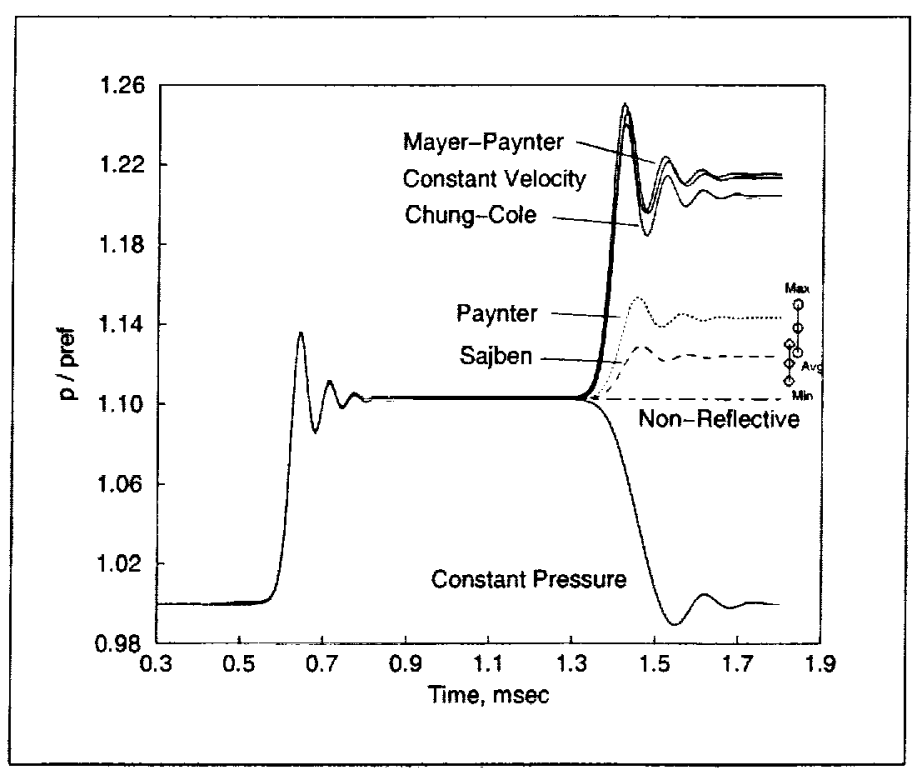

Figure 3. TIME HISTORY OF THE STATIC PRESSURE FOR A $+10 \%$ STEP PRESSURE PERTURBATION IN A STRAIGHT ANNULAR DUCT.

acoustic disturbance is created by the velocity disturbance. At a time of $t=6.1 \mathrm{msec}$ the reflected upstream-travelling acoustic wave reached the sensor. Only the Paynter small-disturbance boundary condition gave a response. The magnitude of the reflected response was quite small at less than $0.4 \%$, which agreed well with the response predicted by Eq. 9 .

\section{UC COMPRESSOR FACE EXPERIMENT}

The experiment by Freund and Sajben (1997) provides the limited experimental data for the interaction of an acoustic pulse with a compressor. The configuration consisted of a straight, annular duct connected to a General Electric T58-3 engine by a short convergent section. The blades of the first stage of the compressor had a stagger angle of 45 degrees at the hub and 60 degrees at the case. The Mach number at the compressor face was Mach 0.2. A planar acoustic pulse was generated by the rapid collapse of a flexible boot located on the hub of the duct. Four sensors along the duct between the boot and the compressor measured the time history of the static pressure. Sensor 1 is located closest to the bump and sensor 4 is closest to the compressor.

The experiment has been simulated by Paynter, Clark, and Cole (1998) using the LAPIN unsteady, quasi-one-dimensional flow code along with the Paynter small-disturbance boundary condition. Comparisons were made to other outflow boundary conditions. Suresh et al. (1999) simulated the experiment by coupling NPARC with the ADPAC turbomachinery code.

The present work simulated the experiment using NPARC while assuming unsteady, inviscid flow and using dynamic grids

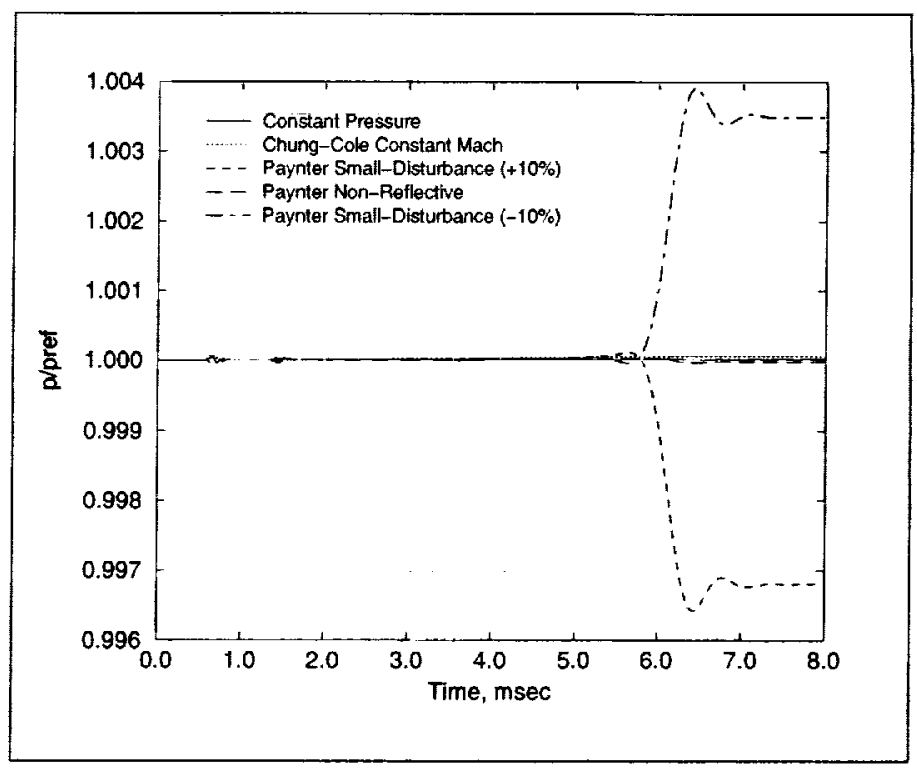

Figure 4. TIME HISTORY OF THE STATIC PRESSURE FOR $+/-10 \%$ STEP CIRCUMFERENTIAL VELOCITY PERTURBATIONS.

to simulate the collapsing bump. The Newton iterative implicit method was used with a constant physical time step of 3.0E-06 seconds, which corresponded to a local Courant number of approximately 0.9 .

Figures 5 to 7 show the time histories of the static pressures at sensors 1,2 , and 3 for the $7.0 \mathrm{msec}$ span beginning when the bump starts to collapse. The lines denoted as "Paynter" used Eq. 5 for the acoustic response coefficient, $\beta$, while the lines denoted as "Paynter-Sajben" used Eq. 7. The ranges of values for $\beta$ are indicated in Fig. 5. Also plotted are the experimental data and LAPIN results. The LAPIN results were computed using an updated version which modeled more accurately the bump collapse and used a $\beta=0.362$ based on $\Gamma=52$ degrees and $M_{c f}=0.2067$. Figure 8 shows the time histories at sensor 2 for the Chung-Cole, Mayer-Paynter, and the constant-velocity boundary conditions. The time history for the constant-pressure boundary condition is not presented, but gave an incorrect response of opposite sign with a magnitude equal to the incident pulse. The time history for the non-reflective is also not presented, but gave a slight response of the correct sign; however, this response was due to the converging duct at the compressor face.

The plots show the acoustic pulse with a magnitude approximately $4 \%$ of the initial steady-state pressure moving downstream. The initial bump height and collapse time were adjusted in the simulations, so that the acoustic pulse matched the observed pulse. The pulse interacted with the compressor face and a reflected acoustic response was generated with an amplitude of approximately $1.5 \%$ of the initial steady-state pressure. In Fig. 


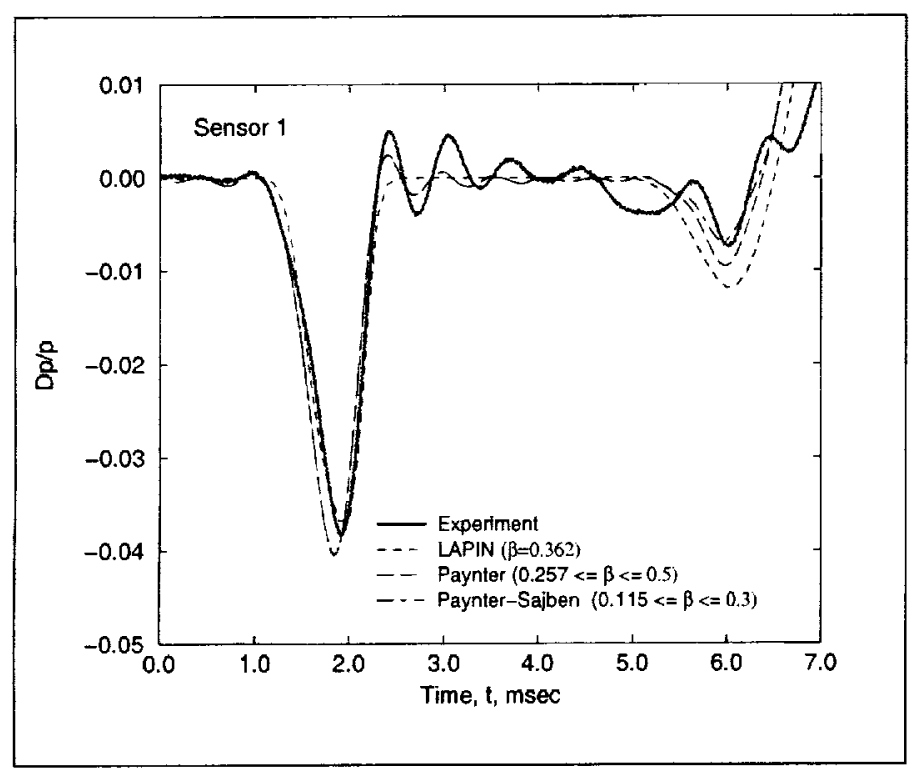

Figure 5. THE TIME HISTORIES OF THE PRESSURE AT SENSOR 1 FOR THE PAYNTER SMALL-DISTURBANCE BOUNDARY CONDITION.

6 , the reflected response is seen at approximately $t=5.3 \mathrm{msec}$. If one sequences through the plots from sensor 3 to sensor 1 , one can see the reflected response travelling upstream (occuring later in time). The Paynter small-disturbance boundary condition under-predicts the magnitude of the response; however, the reflected response from currently existing boundary conditions, as shown in Fig. 8, grossly over-predict the magnitude, which is approximately equal to the magnitude of the pulse. The comparisons with the experiment suffer because the simulations do not account for the initial guide vanes or later stages of the compressor which influence the size and shape of the reflected response.

\section{NASA VARIABLE DIAMETER CENTERBODY INLET}

Simulations of the unsteady, inviscid flow in the NASA variable diameter centerbody inlet (Wasserbauer, Shaw, Neumann, 1974) demonstrate the sensitivity of the outflow boundary conditions in predicting terminal shock motion and tolerance to unstart. The inlet is an axisymmetric, mixed-compression inlet designed for Mach 2.5. A normal terminal shock is located aft of the throat. The steady-state flowfield was computed using NPARC with the Chung-Cole boundary condition imposing a compressor-face Mach number of 0.31 .

The unsteady flow was initiated by a $-2 \%$ step disturbance in the freestream pressure. Figure 9 shows the time history of the axial position of the terminal shock. The shock moved forward as the disturbance passed downstream. The disturbance interacted with the compressor face and an upstream-travelling, acoustic wave was created, which then interacted with the shock.

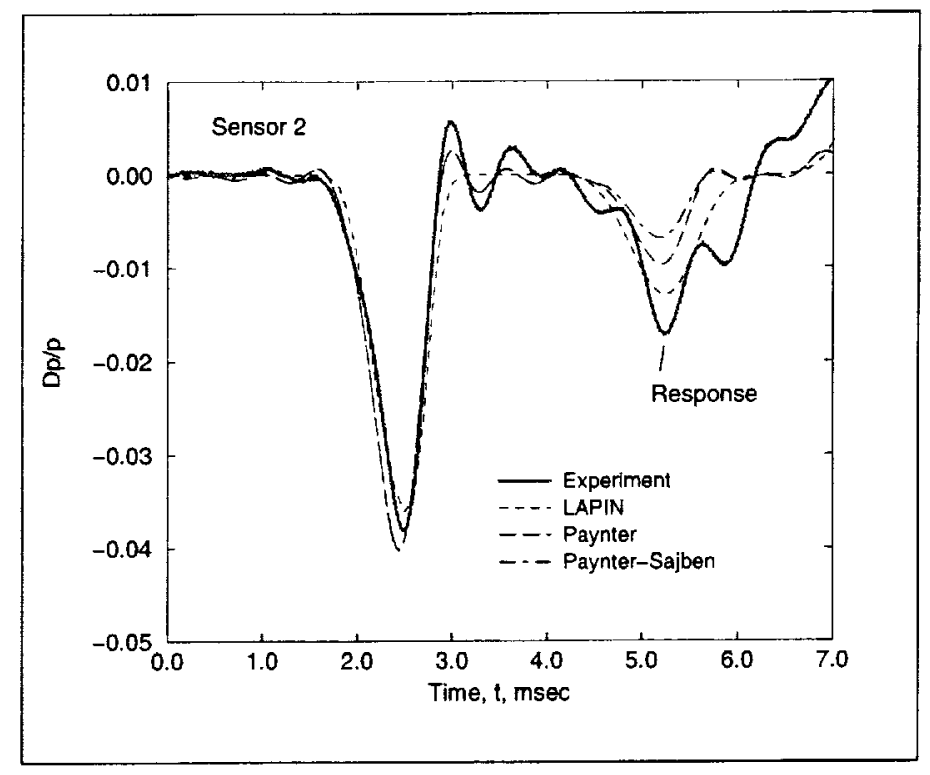

Figure 6. THE TIME HISTORIES OF THE PRESSURE AT SENSOR 2 FOR THE PAYNTER SMALL-DISTURBANCE BOUNDARY CONDITION.

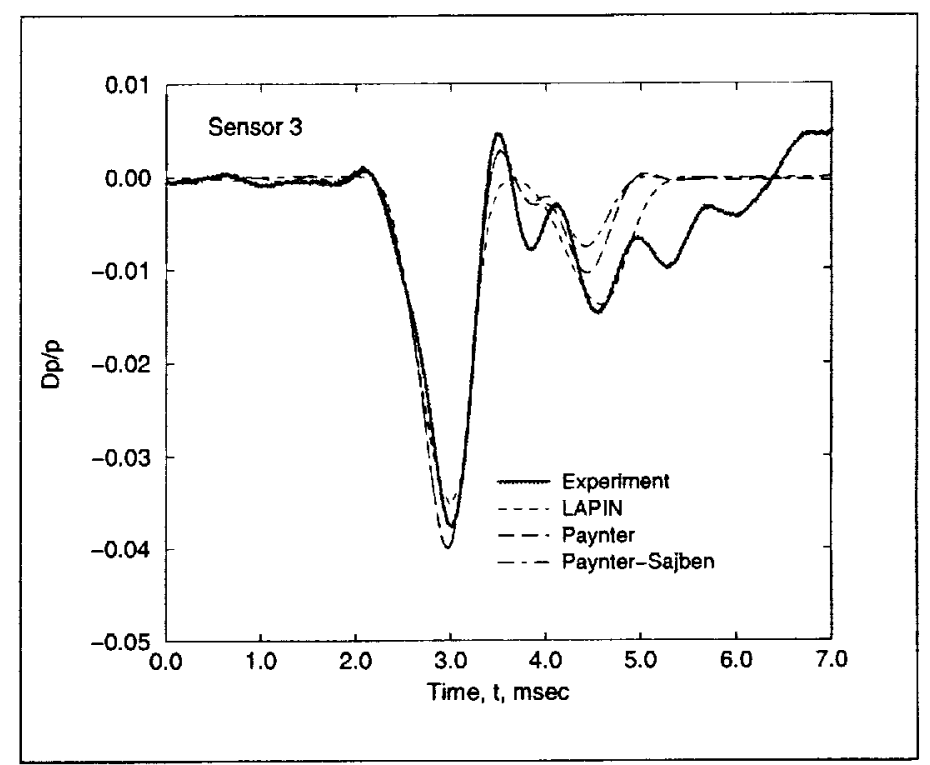

Figure 7. THE TIME HISTORIES OF THE PRESSURE AT SENSOR 3 FOR THE PAYNTER SMALL-DISTURBANCE BOUNDARY CONDITION.

The constant-pressure boundary condition created a compression wave, which results in excessive shock motion with eventual unstart. The Paynter small-disturbance and the Chung-Cole constant-Mach number boundary conditions created reflected expansion waves as the response. The constant-Mach boundary 


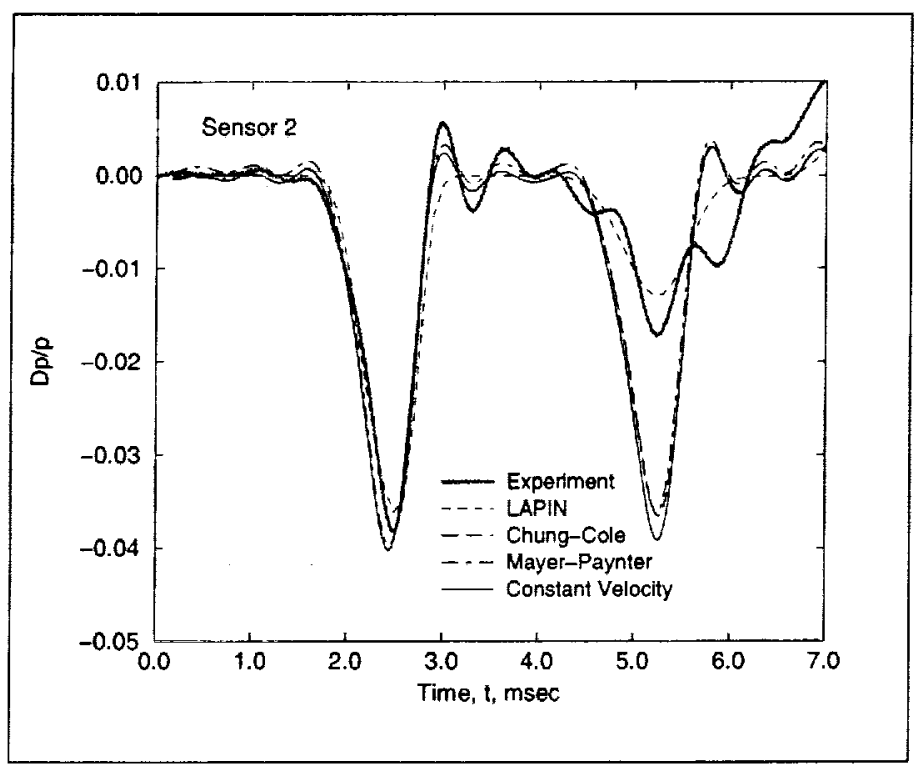

Figure 8. THE TIME HISTORIES OF THE PRESSURE AT SENSOR 2 FOR THE CHUNG-COLE, MAYER-PAYNTER, AND CONSTANTVELOCITY BOUNDARY CONDITIONS.

condition created the stronger response, which results in less forward motion of the shock. Paynter, Clark, and Cole (1998) observed this in the one-dimensional analyses and showed that the behavior became more apparent with stronger disturbances. The result was that the constant-Mach boundary condition would incorrectly overestimate the unstart tolerance.

\section{CONCLUDING REMARKS}

The Paynter small-disturbance compressor-face boundary condition was implemented into a three-dimensional computational fluid dynamics code and demonstrated a marked improvement over existing boundary conditions in predicting the response to unsteady acoustic and convective velocity disturbances interacting with a compressor face.

\section{REFERENCES}

Chung, J.K. and Cole, G.L., 1995, "Comparison of Compressor Face Boundary Conditions for Unsteady CFD Simulations of Supersonic Inlets," AIAA 95-2627.

Chung, J., Slater, J.W., Suresh, A., and Townsend, S.E., 1999, “NPARC v3.1 User's Guide," NASA TM-1999-209058.

Freund, D.D. and Sajben, M., 1997, "Reflection of Large Amplitude Acoustic Pulses from an Axial Flow Compressor," AIAA 97-2879.

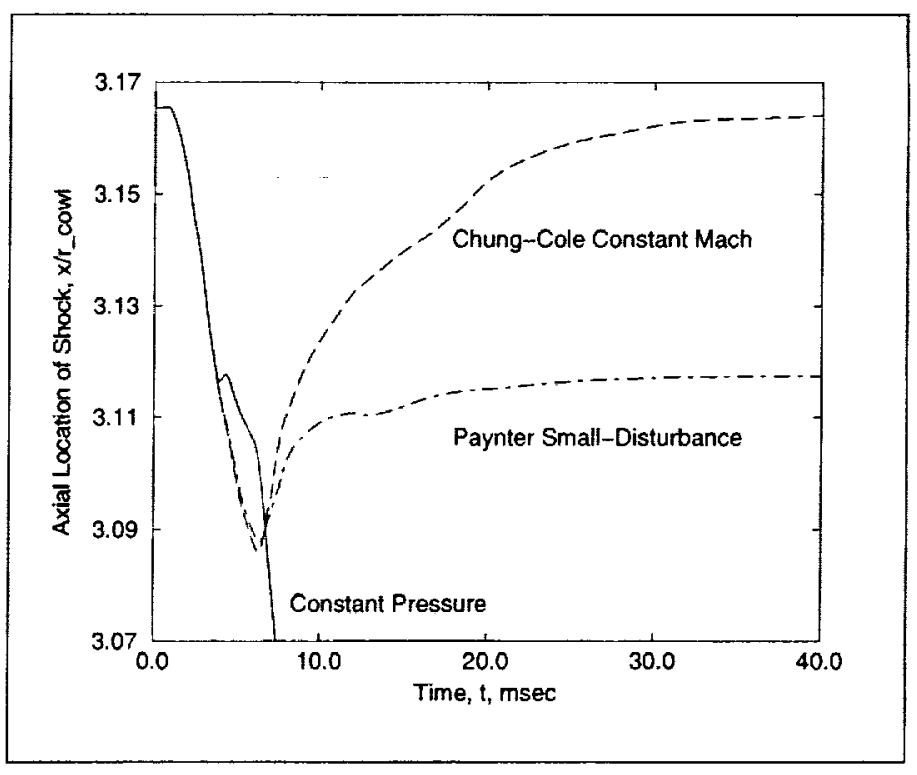

Figure 9. THE TIME HISTORIES OF THE TERMINAL SHOCK POSITION SUBJECT TO A FREESTREAM PRESSURE DISTURBANCE.

Mayer, D.W. and Paynter, G.C., 1994, "Boundary Conditions for Unsteady Supersonic Inlet Analyses," AIAA Joumal, Vol. 32, No. 6, pp. 1200-1206.

Paynter, G.C., 1997, "Response of a Two-Dimensional Cascade to an Upstream Disturbance," AIAA Joumal, Vol. 35, No. 3, pp. 434-440,

Paynter, G.C., Clark, L.T., and Cole, G.L., 1998, "Modeling the Response from a Cascade to an Upstream Acoustic Disturbance," AIAA 98-0953.

Paynter, G.C., 1998, "Modeling the Response From a Cascade to an Upstream Convective Velocity Disturbance," AIAA Paper 3570.

Sajben, M. 1999, "Prediction of Acoustic, Vorticity, and Entropy Waves Generated by Short-Duration Acoustic Pulses Incident on a Blade Row," 1999-GT-148.

Shapiro, A.H., 1954, The Dynamics and Thermodynamics of Compressible Fluid Flow, Ronald Press Company, New York.

Suresh, A., Townsend, S.E., Cole, G.L., Slater, J.W., and Chima, R., 1999, "Analysis of Inlet-Compressor Acoustic Interactions Using Coupled CFD Codes", AIAA 99-0749.

Wasserbauer, J.F., Shaw, R.J., and Neumann, H.E., 1975, "Design of a Very-Low-Bleed Mach 2.5 Mixed-Compression Inlet with 45 Percent Internal Contraction", NASA TM X-3135. 
$+$

.

. 
Public reporting burden for this collection of information is estimated to average 1 hour per response, including the time for reviewing instructions, searching existing data sources gathering and maintaining the data needed, and completing and reviewing the collection of information. Send comments regarding this burden estimate or any other aspect of this collection of information, including suggestions for reducing this burden, to Washington Headquarters Services, Directorate for Information Operations and Reports, 1215 Jefferson Davis Highway, Sutte 1204, Artington, VA 22202-4302, and to the Office of Management and Budget, Paperwork Reduction Project (0704-0188), Washington, DC 20503.

\begin{tabular}{l|l|l} 
1. AGENCY USE ONLY (Leave blank) & 2. REPORT DATE & 3. REPORT TYPE AND DATES COVERED
\end{tabular} Technical Memorandum

\section{TITLE AND SUBTITLE}

March 2000

5. FUNDING NUMBERS

Implementation of a Compressor Face Boundary Condition Based on Small Disturbances

\section{AUTHOR(S)}

WU $-714-04-50-00$

John W. Slater and Gerald C. Paynter

7. PERFORMING ORGANIZATION NAME(S) AND ADDRESS(ES)

National Aeronautics and Space Administration

John H. Glenn Research Center at Lewis Field

Cleveland, Ohio 44135-3191

8. PERFORMING ORGANIZATION

REPORT NUMBER

E-12193

9. SPONSORING/MONITORING AGENCY NAME(S) AND ADDRESS(ES)

10. SPONSORING/MONITORING AGENCY REPORT NUMBER

National Aeronautics and Space Administration

Washington, DC 20546-0001

NASA TM-2000-209945

ASME 2000-GT-0005

\section{SUPPLEMENTARY NOTES}

Prepared for the 45th International Gas Turbine and Aeroengine Technical Congress sponsored by the American Society of Mechanical Engineers, Munich, Germany, May 8-11, 2000. John W. Slater, NASA Glenn Research Center, and Gerald C. Paynter, The Boeing Company, P.O. Box 3707, Seattle, Washington 98124. Responsible person, John W. Slater, organization code 5850, (216) 433-8513.

12a. DISTRIBUTIONAVAILABILITY STATEMENT 12b. DISTRIBUTION CODE

Unclassified - Unlimited

Subject Category: 07

Distribution: Nonstandard

This publication is available from the NASA Center for AeroSpace Information, (301) 621-0390.

13. ABSTRACT (Maximum 200 words)

A compressor-face boundary condition that models the unsteady interactions of acoustic and convective velocity disturbances with a compressor has been implemented into a three-dimensional computational fluid dynamics code. Locally one-dimensional characteristics along with a small-disturbance model are used to compute the acoustic response as a function of the local stagger angle and the strength and direction of the disturbance. Simulations of the inviscid flow in a straight duct, a duct coupled to a compressor, and a supersonic inlet demonstrate the behavior of the boundary condition in relation to existing boundary conditions. Comparisons with experimental data show a large improvement in accuracy over existing boundary conditions in the ability to predict the reflected disturbance from the interaction of an acoustic disturbance with a compressor.

\begin{tabular}{|c|c|c|}
\hline $\begin{array}{l}\text { 14. SUBJECT TERMS } \\
\text { Computational fluid dyn }\end{array}$ & nics; Inlets; Compressors & \\
\hline $\begin{array}{l}\text { 17. SECURITY CLASSIFICATION } \\
\text { OF REPORT } \\
\text { Unclassified }\end{array}$ & $\begin{array}{l}\text { 18. SECURITY CLASSIFICATION } \\
\text { OF THIS PAGE } \\
\text { Unclassified }\end{array}$ & $\begin{array}{l}\text { 19. SECURITY CLASSIFICATION } \\
\text { OF ABSTRACT } \\
\text { Unclassified }\end{array}$ \\
\hline
\end{tabular}

NSN 7540-01-280-5500 